\title{
SOCIAL COSTS OF ROAD CRASHES: AN INTERNATIONAL ANALYSIS
}

\author{
Wim Wijnen \\ W2Economics / Institute for Road Safety Research SWOV \\ E-mail: RoadSafetyEconomics@gmail.com
}

\begin{abstract}
Information about the social costs of road crashes is important for evidence-based policy making. It provides insight in the consequences of road crashes for the economy and social welfare, and it is used in cost-benefit analyses in order to estimate the social return of investments in road safety and to prioritize (road safety) measures. This paper provides an international overview of the most recent estimates of the social costs of road crashes: total costs, value per casualty and breakdown in cost components. It answers the question to what extent the total social costs of road crashes differ between countries and what the explanations for these differences are. The analysis is based on national reports about costs of road crashes of 16 countries, of which nine high income countries (HICs) and seven low and middle income countries (LMICs).

The analysis shows that the share of social costs of road crashes in HICs ranges from 1.0 to $4.6 \%$ of the gross domestic product (GDP) with an average of $2.6 \%$. The main explanations for differences between these countries are differences in methodologies regarding valuation of human costs and correction for underreporting. Excluding countries that do not use a 'willingness to pay' method (that is internationally recommended) for estimating human costs and countries that do not correct for underreporting, results in an average share of the costs of 3.7\% of GDP. For LMICs that do correct for underreporting the share in GDP ranges from 1.2 to $3.0 \%$. However, none of the LMICs included has performed a willingness to pay study into the human costs. A major part of the costs is related to injuries: an average share of $50 \%$ for both HICs and LMICs. The share of fatalities in the costs is $20 \%$ and $30 \%$ respectively. Prevention of injuries is thus important to bring down the socio-economic burden of road crashes.

The paper shows that there are a number of methodological differences between countries regarding cost components that are taken into account and regarding the methods used to estimate specific cost components. In order to be able to make sound comparisons of the costs of road crashes across countries, (further) harmonization of cost studies is recommended. This can be reached by updating and improving international guidelines and applying them in future cost studies. The information regarding some cost components, particularly human costs and property damage, is poor and more research into these cost components is recommended.
\end{abstract}

\section{INTRODUCTION}

Information about the social costs of road crashes is important for evidence-based policy making. It provides insight into the consequences of road crashes for the economy and social welfare. Information about the costs is useful for comparing costs of road crashes with costs in other policy areas, which is an input for priority setting across policy areas. Information 
about costs of road crashes is also needed in cost-benefit analyses (CBA) that are used to estimate the social return of investments in road safety and to help prioritizing (road safety) measures. In CBA the costs per casualty or crash are used to estimate the benefits of road safety improvements.

International comparison of the costs of road crashes is useful to gain insight in differences in the economic burden of road crashes across countries, and is used as an input for estimating global road crash costs. Based on international comparisons, the social costs of road crashes have previously been estimated at about $1 \%$ of Gross Domestic Product (GDP) in low income countries to about 2\%-3\% in high income countries (Jacobs et al, 2000; Elvik, 2000). However, these estimates are based on costs studies in the 90s or earlier, and probably underestimate the costs of road crashes (WHO, 2004). Other international comparisons (e.g. Elvik 1995; Trawén et al, 2002; Hakkert \& Wesemann, 2005) are aimed at comparing the costs per fatality and/or serious injury, which is useful for CBAs but does not provide insight into the full social costs of road crashes. Also comparing the methods used to estimate these costs is very useful, since previous studies show that methodological differences are an important explanation for differences in cost estimates.

This paper provides an international overview of the most recent estimates of the social costs of road crashes in 16 countries. In section 2 the method used for this international comparison and the selection of countries is briefly explained. Section 3 provides an overview of the costs components that are taken into account in cost studies in these countries, and discusses the methods used to estimate these costs. In section 4 the results of costs studies are compared, in particular the total costs of road crashes and the share in GDP, values per casualty, distribution of the total costs among crash severity and the breakdown in cost components. Section 5 contains a discussion of the main results and section 6 gives conclusions and recommendations.

\section{METHOD AND SELECTION OF COUNTRIES}

The international comparison of the costs of road crashes in this paper is based on the most recent national reports or papers about these costs. Only countries for which a sufficiently detailed report or paper is available about the costs and the methods used to estimate them, written in English, German or Dutch, are included. This resulted in a selection of 16 countries, of which eight Asian countries, six European countries, Australia and the US. The costs of road crashes in the Asian countries, most of which are low or middle income countries, have been studied in the context of a larger study by the Asian Development Bank (ADB, 2005a). For each Asian country the costs of road crashes have been studied and published separately, enabling us to include these countries in this overview. Among the selected countries are nine high income countries, five middle income countries and two low income countries. Table 1 shows the countries that are included, the year for which the costs of road crashes have been estimated, and the reference(s) for each country.

Previous studies (Jacobs, 2000) found that the costs of road crashes as a share of GDP depend on the economic performance of a country. Therefore, in this analysis the costs of road crashes in high income countries (HICs) will be compared to those in low and middle income countries (LMICs). Table 1 shows to which income category each country belongs, as classified by the World Bank on the basis on gross national income per capita. 
Table 1: Countries included, income category (high/middle/low income country), year for which costs of road crashes have been estimated and sources.

\begin{tabular}{|l|l|l|l|}
\hline Country & Income category & Year & Sources \\
\hline Australia & HIC & 2006 & BITRE (2009) \\
\hline Austria & HIC & 2004 & Herry et al. (2008) \\
\hline Belgium & HIC & 2002 & $\begin{array}{l}\text { De Brabander \& Vereeck (2005), De } \\
\text { Brabander (2005) }\end{array}$ \\
\hline Cambodia & LIC & 2002 & ABD (2005b) \\
\hline Germany & HIC & 2005 & Baum et al. (2007) \\
\hline Indonesia & MIC & 2002 & ABD (2005c) \\
\hline Laos & MIC & 2003 & ABD (2005d) \\
\hline Myanmar & LIC & 2003 & ABD (2005e) \\
\hline Netherlands & HIC & 2009 & $\begin{array}{l}\text { De Wit \& Methorst (2012), Wijnen } \\
\text { (2012) }\end{array}$ \\
\hline Philippines & MIC & 2002 & ABD (2005f) \\
\hline Singapore & HIC & 2001 & ABD (2005g) \\
\hline Switzerland & HIC & 2003 & Sommer et al. (2007), Ecoplan (2002) \\
\hline Thailand & MIC & 2002 & ABD (2005h) \\
\hline UK & HIC & 2010 & $\begin{array}{l}\text { DfT (2011), McMahon (1994), Hopkin } \\
\text { \& O’Reilly (1993) }\end{array}$ \\
\hline US & HIC & 2000 & Blincoe et al. (2002) \\
\hline Vietnam & MIC & 2003 & ABD (2005i) \\
\hline
\end{tabular}

\section{COST COMPONENTS AND METHODS}

In international guidelines, e.g. the European guideline COST 313 (Alfaro et al., 1994), five components of the costs of road crashes are distinguished (see also SWOV, 2011):

- medical costs: costs resulting from the treatment of casualties, e.g. costs of hospital stay, rehabilitation, medicines and adaptations for the handicapped;

- production loss: loss of production and income resulting from the temporary or permanent disability of the injured, and the complete loss of production of fatalities;

- human costs: immaterial costs through suffering, pain, sorrow and loss of quality of life;

- property damage: damage to vehicles, freights, roads and fixed roadside objects;

- administrative costs: in this category costs of police, fire brigade, law courts and administrative costs of insurers are taken into account.

All countries in this overview include these five cost components in their estimate of the costs of road crashes, and these costs have a share of at least 93\% in total costs (see below). The LMICs do not take into account other cost components, while most HICs additionally include costs of congestion resulting from road crashes. Some HICs also include costs of unavailability of damaged vehicles.

Besides these costs, avoidance costs may be a relevant cost component (Van Wee, Hagenzieker \& Wijnen, forthcoming). These are the costs that occur when people adapt their travel behaviour because of perceived low safety levels, like changing travel mode, route, 
destinations or their choice whether or not to travel at all. Examples are older persons that may prefer to stay at home because they think travelling is too risky, or parents that choose to bring their children to school by car instead of by bicycle. Studies into the avoidance costs related to congestion have been done in the Netherlands, and these costs appear to have a significant share (30 to 40\%) in total congestion costs (KiM, 2012). No such studies have been done in the field of road safety however.

In the remainder of this section we discuss the methods used the estimate the main costs components: human costs, property damage and production loss.

\subsection{Human costs}

According to international guidelines (e.g. Alfaro et al, 1994) and state of the art economic theory (e.g. Boardman et al., 2006), human costs should be estimated by using a 'willingness to pay' (WTP) method. This means that the amount of money that people are prepared to pay for a reduction in crash risk is estimated by using a 'stated preference' (SP) method or 'revealed preference' (RP) method. RP methods value risk reductions on the basis of actual behaviour, for example purchasing behavior regarding safety provisions, while SP methods use questionnaires in which people, directly or indirectly, are asked how much they are willing to pay for safety provisions (SWOV, 2012). From the WTP for risk reductions the 'value of a statistical life' (VOSL) is derived. The VOSL comprises the valuation of human costs as well as a value of consumption loss. Thus, subtracting consumption loss from the VOSL results in the value of human costs (see e.g. Evans, 2001).

Table 2 gives an overview of the VOSL and/or human costs per fatality (dependent on which values are documented) for each country, the year for which the VOSL has been estimated, and the method. In most (six) HICs included in this overview human costs are based on WTP. Three of them use a country-specific VOSL, and the other three countries use a standard European VOSL that has been determined in studies like HEATCO (Bickel et al, 2006) and UNITE (Nellthorp et al., 2001). Australia and Germany estimate the human costs on the basis of compensation payments as determined in law courts or statutory values. Singapore and all LMICs use a rule of thumb as proposed in a guideline for cost studies in developing countries, meaning that human costs are estimated as fixed percentages of the total costs per fatality, serious injury and slight injury respectively (BRS\&TRL, 2003). These percentages are more or less arbitrary values from the 1980s, and they are originally based on the difference between output and consumption in the UK. This amount was added to net production losses in order to prevent elderly having a negative 'value' (TRL, 1995). Table 2 shows that the values per fatality based on WTP are much higher than those based on compensation payments. Also the rule of thumb that Asian countries use leads to relatively low values, in absolute terms as well as as a percentage of the total costs of a fatality: in HICs that use a WTP value human costs have a share of $45 \%$ to $77 \%$ in the costs of a fatality, whereas this percentage is $18 \%$ to $28 \%$ in LMIC.

Almost all countries also estimate the human costs of (all) injuries. In the Netherlands and the Philippines only human costs of serious injuries are included, in all other countries the costs of both serious and slight injuries are estimated. Country-specific values for injuries are only available in the UK and the US. In the UK a WTP study has been carried out for serious and slight injuries. In the US the values of injuries are based on 'quality adjusted life years' (QALYs). For five injury categories, based on the Maximum Abbreviated Injury Scale (MAIS), the number of QALYs has been estimated and the human losses are calculated using 
a value per QALY. Australia and Germany use compensation payments as an indicator for the human costs of injuries, and in the Asian countries the rule of thumb mentioned above is applied. The other countries use the ratio between the human costs of a (serious or slight) injury and the VOSL that is found in other countries or recommended in European studies. These ratios are based on studies into the human costs of road injuries in the UK (Hopkin \& O’Reilly, 1993; O’Reilly et al., 1995) and Sweden (Persson, 2004).

Table 2: Value of a statistical life (VOSL), human costs per fatality, year for which VOSL has been estimated, and methods used.

\begin{tabular}{|c|c|c|c|c|}
\hline Country & $\begin{array}{l}\text { VOSL } \\
\text { (million US\$ } \\
\text { 2010)* }\end{array}$ & $\begin{array}{l}\text { Human costs } \\
\text { per fatality } \\
\text { (million US\$ } \\
\text { 2010)* }\end{array}$ & $\begin{array}{l}\text { Base year } \\
\text { VOSL }\end{array}$ & Method \\
\hline \multicolumn{5}{|l|}{ HICs } \\
\hline Australia & - & 0.3 & n.a. & Compensation payments \\
\hline Austria & 2.3 & 1.4 & 1998 & WTP, EU-value \\
\hline Belgium & 2.7 & - & 1998 & WTP, EU-value \\
\hline Germany & - & 0.04 & n.a. & Compensation payments \\
\hline Netherlands & 2.9 & 2.4 & 2001 & WTP, country-specific \\
\hline Singapore & & 0.4 & n.a. & $\%$ cost fatality, rule of thumb \\
\hline Switzerland & 2.2 & - & 1998 & WTP, EU-value \\
\hline UK & - & 1.8 & 1991 & WTP, country-specific \\
\hline US & - & 3.0 & 1990 & WTP, country-specific \\
\hline \multicolumn{5}{|l|}{ LMICs } \\
\hline Cambodia & - & 0.007 & n.a. & $\%$ cost fatality, rule of thumb \\
\hline Indonesia & - & 0.03 & n.a. & $\%$ cost fatality, rule of thumb \\
\hline Laos & - & 0.002 & n.a. & $\%$ cost fatality, rule of thumb \\
\hline Myanmar & - & 0.006 & n.a. & $\%$ cost fatality, rule of thumb \\
\hline Philippines & - & 0.02 & n.a. & $\%$ cost fatality, rule of thumb \\
\hline Thailand & - & 0.04 & n.a. & $\%$ cost fatality, rule of thumb \\
\hline Vietnam & - & 0.01 & n.a. & $\%$ cost fatality, rule of thumb \\
\hline
\end{tabular}

* The values in local currencies are converted into US\$ price level 2010 using GDP deflators (World Bank, 2012) and Purchasing Power Parities (World Bank, 2012; OECD, 2012).

\subsection{Production loss}

To estimate production loss the 'human capital' method is used in all countries in this overview. In this approach the (loss of) productive capacity of a human being is valued, based on figures of productivity or income per capita, and estimates of the period of time casualties are unable to work. In the literature the human capital approach has been considered as an approach to value human life, as an alternative for the WTP approach. However, the human capital approach is used to estimate (loss of) production, while the WTP approach is used to estimate (loss of) quality of life. Therefore, the human capital approach and the WTP approach should be considered as complementary (Wijnen et al., 2009). Both approaches 
include a component of consumption loss however, which means that a correction is needed to avoid double counting. In most countries consumption loss is deducted from the VOSL, resulting in human losses. Consumption loss is then included in production loss (known as 'gross production loss'). Exceptions are Belgium and Switzerland that include consumption loss in the human costs. These two countries calculate the net production loss (gross production loss minus consumption loss).

Four countries (Australia, Germany, UK and US) take into account unpaid production loss like household work, in addition to the loss of market production. To calculate this production loss surveys of time spending are used, in combination with indicators for the costs of time (like wage or costs of hiring personnel). Loss of unpaid production can have a significant share in total production loss: in the US for example about $25 \%$ of all production loss concerns unpaid work.

Finally, four countries (Australia, Germany, Switzerland and US) separately estimate 'friction costs': the costs of recruitment and training new employees. In Switzerland and the US these cost are about $5 \%$ of production loss, and in Australia and Germany less than $1 \%$.

\subsection{Property damage}

The majority of property damage concerns damage to vehicles. In most countries this damage is based on insurance data. One of the major problems regarding this cost component is the fact that not all damage is claimed, because of no-claim premiums for example, and that not all damage is covered by insurances. However, all countries in this overview have included an estimate of damage that is not claimed and/or not covered by insurances. In most countries this is done by deriving the average property damage per crash (in most cases for different crash severities) from insurance data, and estimating the number of crashes on the basis of police registrations, insurance data, and assumptions. A problem with this approach is that the estimate of the number of crashes, particularly property damage only crashes, is uncertain due to incomplete registration. In other countries the property damage estimates are based on the payments by insurance companies, and a separate estimate of the non-claimed damage using insurance data, crash registrations and/or assumptions. These estimates of non-claimed damage range from $22 \%$ (Austria) to about $50 \%$ (Netherlands) of total property damage. The UK is the only country where a study into the non-claimed damage has been carried out using questionnaires (Taylor, 1990). This study showed that in about half of the cases a claim is submitted at an insurance company, and that in those cases the average damage per case is about three times higher than in cases without a claim.

Nine countries, among which three LMICs, take into account other property damage besides vehicle damage, mainly damage to infrastructure. In most cases damage registrations by road authorities are used to estimate this property damage. This other property damage is estimated at $1 \%$ of total property damage in Australia, about 10\% in Austria, Germany and Myanmar, up to 20\% in Loa PDR (for other countries this percentage is not documented). 


\section{COMPARISON OF THE COSTS OF ROAD CRASHES}

\subsection{Total costs and costs per casualty}

Table 3 shows the costs of road crashes for each country. The costs (expressed in the local currency) and the share in GDP are mainly taken from the reports per country (see Table 3). ${ }^{*}$ In case the share in GDP is not stated in the country report, the share in GDP has been calculated using GDP figures published by the World Bank (2012). The costs are converted into US\$ price level 2010, using GDP deflators (World Bank, 2012) and Purchasing Power Parities (World Bank, 2012; OECD, 2012).

In HICs the share of the costs of road crashes in GDP ranges from 0.5 to $4.6 \%$, with an (unweighted) average of $2.6 \%$. The estimates of the two countries with the lowest share (Singapore and the UK) do not include a correction for underreporting of road crashes however, leading to a significant underestimation. In the UK for example, the costs of all crashes may be twice as high if such a correction would have been applied (DfT, 2011). If we exclude these two countries, the two HICs that do not use a WTP method to estimate the human costs, Australia and Germany, have the lowest share in GDP of the remaining countries. As human costs have a great share in the total costs (see below), the method used to estimate these costs has a considerable influence on the total costs. If those countries that do not correct for underreporting and those that do not use a WTP method (as recommended by international guidelines) are excluded, the average share of the cost of road crashes ranges from $2.2 \%$ to $4.6 \%$ of GDP with an average of $3.7 \%$. The average share of the costs of road crashes in GDP in LMICs, that all do correct for underreporting, ranges from $1.8 \%$ to $3.0 \%$ with an average of $2.2 \%$. The share of the costs in GDP is thus considerably lower than in HICs, especially HICs that use a WTP method.

Table 3: Total costs of road crashes and share in GDP

\begin{tabular}{|c|c|c|c|c|}
\hline Country & $\begin{array}{l}\text { Costs, } \\
\text { local } \\
\text { currency }\end{array}$ & Currency, year & $\begin{array}{l}\text { Costs, US\$ } \\
2010\end{array}$ & Share in GDP \\
\hline \multicolumn{5}{|l|}{ HICs } \\
\hline Australia & 17,849 & mln AUD, 2006 & 13,596 & $1.7 \%$ \\
\hline Austria & 10,158 & mln Euro, 2004 & 13,223 & $4.3 \%$ \\
\hline Belgium & 12,524 & mln Euro, 2002 & 16,347 & $4.6 \%$ \\
\hline Germany & 31,477 & mln Euro, 2005 & 40,644 & $1.4 \%$ \\
\hline Netherlands & 12,496 & mln Euro, 2009 & 15,074 & $2.2 \%$ \\
\hline Singapore & 699 & mln SD, 2001 & 749 & $0.5 \%$ \\
\hline Switzerland & 14,078 & mln CHF, 2003 & 10,038 & $3.2 \%$ \\
\hline UK & 14,945 & mln Pound, 2010 & 22,675 & $1.0 \%$ \\
\hline US & 433,476 & mln USD, 2000 & 542,303 & $4.3 \%$ \\
\hline Average HICs & & & & $2.6 \%$ \\
\hline
\end{tabular}

\footnotetext{
* In the US human costs are not taken into account in the total costs, but they are included in the costs per casualty. For this analysis we calculated the total human costs in the US on the basis of number of casualties and costs per casualty, and added them to the total costs in the US.
} 


\begin{tabular}{|l|r|l|r|r|}
\hline & & & & \\
\hline LMICs & & & & $1.8 \%$ \\
\hline Cambodia & 66,064 & mln USD, 2002 & 98,890 & $2.9 \%$ \\
\hline Indonesia & 41,396 & billion Rupiah, 2002 & 15,289 & $2.7 \%$ \\
\hline Laos & 47,383 & 1000 USD, 2003 & 78,862 & $3.0 \%$ \\
\hline Myanmar & 94,814 & mln MK, 2003 & 423 & $2.6 \%$ \\
\hline Philippines & 105,260 & mln P, 2002 & 6,188 & $2.1 \%$ \\
\hline Thailand & 115,932 & mln B, 2002 & 8,818 & $2.0 \%$ \\
\hline Vietnam & 11,034 & billion D, 2003 & 3,041 & $2.2 \%$ \\
\hline Average LMICs & & & & \\
\hline
\end{tabular}

Differences between countries regarding the share of the costs in GDP can be explained by differences in the number of crashes and casualties as well as by differences in the costs per crash or casualty (and methods used to estimate these costs). Tabel 4 shows the costs per casualty (fatalities, serious injuries and slight injuries) or crash (property damage only, PDO). The costs per casualty include crash costs like property damage and administrative costs. ${ }^{*}$ It shows that the costs per fatality in HICs are much higher than the costs in LMICs. This is mainly explained by differences in the valuation of human costs, since human costs have a major share in the costs per fatality. However, also within the HIC group there major differences due to differences in methodology. In Australia, Germany and Singapore the costs per fatality are relatively low, which is explained by the fact that these countries do not apply a WTP method.

The costs per serious and slight injury are more difficult to compare because of differences in the definitions of a serious and slight injury. However, table 4 shows that the costs per serious and slight injury in LMICs are, not surprisingly, much lower than in HICs. Within the HIC group the costs per serious and slight injury in Australia, Germany and Singapore are again relatively low because of the method used to estimate human costs of injuries. The costs per slight injury in the Netherlands are relatively low because human costs are not taken into account for these injuries.

Table 4: Costs per casualty (fatalities, serious injuries and slight injuries) and per crash (property damage only), US\$, price level 2010

\begin{tabular}{|l|r|r|r|r|}
\hline Country & \multicolumn{2}{|l|}{ Costs per casualty } & \multicolumn{2}{l|}{ Costs per crash } \\
\hline & Fatality & \multicolumn{1}{l|}{ Serious injury } & \multicolumn{1}{l|}{ Slight injury } & Property damage only \\
\hline HICs & & & & 6,093 \\
\hline Australia & $1,634,278$ & 162,888 & 9,027 & 4,523 \\
\hline Austria & $2,731,884$ & 323,291 & 23,193 & n.a. \\
\hline Belgium & n.a. & n.a. & n.a. & 3,019 \\
\hline Germany & $1,064,498$ & 110,288 & 4,501 & 3,566 \\
\hline Netherlands & $2,645,759$ & 284,281 & $6,370^{3}$ & \\
\hline
\end{tabular}

\footnotetext{
* In some countries the costs per casualty only include injury related costs (medical costs, production loss and human costs). In those cases we have calculated the crash related costs per casualty on the basis of costs per crash (property damage and administrative costs) and the number of casualties (per injury category) per crash, and added them to the costs per casualty.
} 


\begin{tabular}{|l|r|r|r|r|}
\hline Country & \multicolumn{3}{|l|}{ Costs per casualty } & \multicolumn{2}{l|}{ Costs per crash } \\
\hline Singapore & $1,507,246$ & 135,595 & 12,982 & 3,591 \\
\hline Switzerland & $2,177,421$ & $393,954^{1}$ & $19,277^{1}$ & n.a. \\
\hline UK & $1,935,609$ & 217,500 & 16,774 & 2,295 \\
\hline US & $3,388,741$ & $261,444^{2}$ & $10,470^{2}$ & 2,549 \\
\hline & & & & 723 \\
\hline LMICs & & & & 247 \\
\hline Cambodia & 30,292 & 11,897 & 937 & 419 \\
\hline Indonesia & 120,894 & 7,891 & 2,246 & 3,213 \\
\hline Laos & 11,988 & 3,528 & 641 & 3,238 \\
\hline Myanmar & 25,184 & 8,300 & 1,774 & 1,499 \\
\hline Philippines & 121,487 & 13,531 & 3,710 & 568 \\
\hline Thailand & 216,993 & 10,821 & 1,610 & - \\
\hline Vietnam & 86,495 & $22,296^{4}$ & & - \\
\hline
\end{tabular}

${ }^{1}$ Switzerland distinguishes four injury categories and three age groups; the costs per serious injury are an average of the three most serious injury categories, weighted by number of casualties and age.

${ }^{2}$ The US calculates the costs per MAIS-category (Maximum Abbreviated Injury Scale); the costs per serious and slight injury are an average of MAIS 2-5 and MAIS 0-1 respectively.

${ }^{3}$ The Netherlands distinguishes two slight injury categories; the costs slight injury are a weighted average of these two categories.

${ }^{4}$ Thailand does not distinguish between serious and slight injuries; this figure refers to all injuries.

The higher costs per casualty are an explanation for the higher share of the costs of road crashes in GDP in HICs. However, also the number of casualties determines the share of the costs in GDP. This explains why the share of the costs in GDP in some HICs (like the Netherlands and Switzerland) is lower, or not much higher, than in some LMICs. A better road safety performance in HICs leads to relatively low costs (as a percentage of GDP), despite higher costs per casualty.

\subsection{Costs per severity category}

Figure 1 shows the distribution of the total costs among fatalities, serious injuries, slight injuries and property damage only crashes. In Singapore and UK only the costs of registered casualties are calculated, leading to an upward bias in the share of more severe casualties. For that reason these two countries are excluded here. For Belgium and Vietnam this distribution is not known.

The figures show that both in HICs and LMICs the majority of the costs, on average about $50 \%$, is related to injuries, of which about two thirds to serious injuries. Fatalities account for about 20\% (HICs) to 30\% (LMICs) of the costs, and about a quarter to a fifth of the costs result from property damage only crashes. The main difference between HICs and LMICs is that the share of fatalities in the total costs is higher in LMICs. This is probably explained by the relatively high number of fatalities in LMICs as compared to the number of injuries.

Figure 1: Distribution of total costs among fatalities, serious injuries, slight injuries and property damage only (PDO) crashes. 


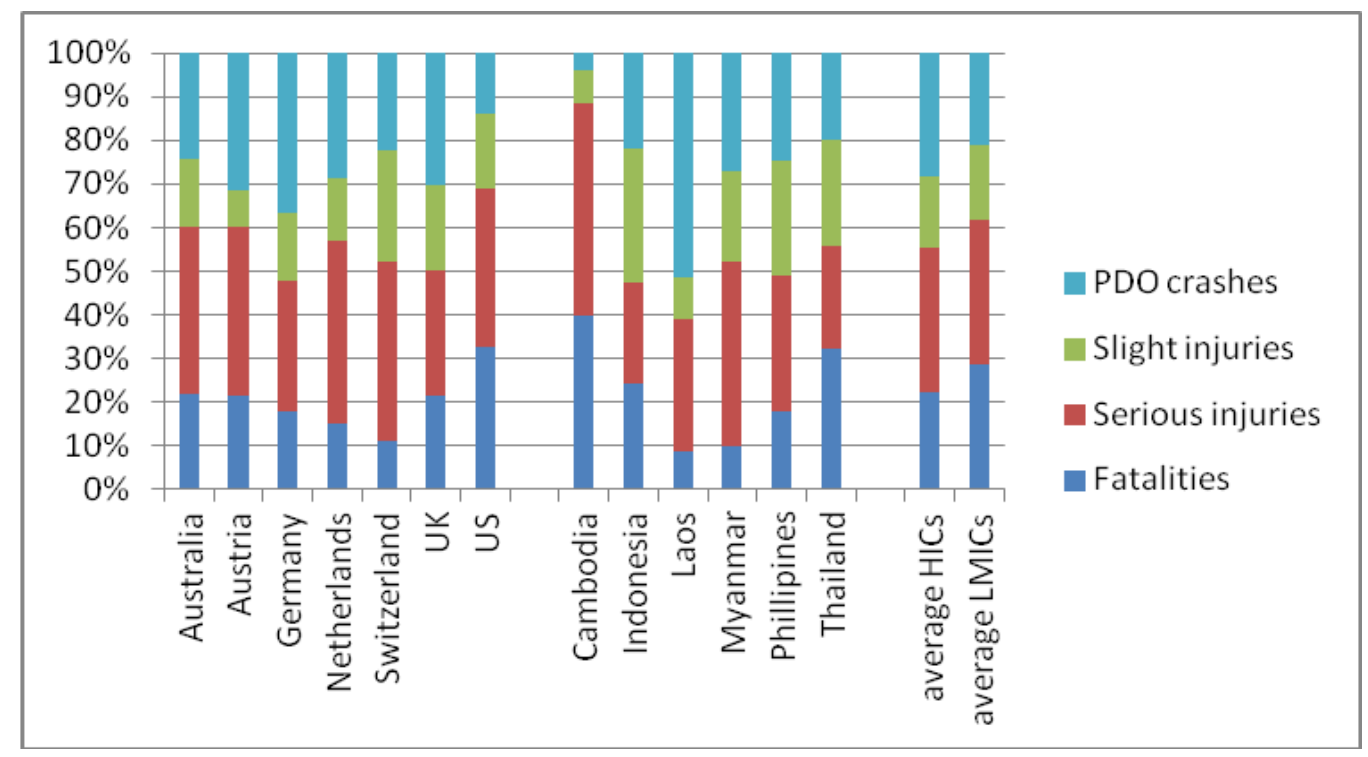

\subsection{Distribution among cost components}

Figure 2 shows the shares of the five main cost components in the total costs of road crashes for each country and the averages for HICs and LMICs. In the HICs human costs have a major share in the total costs: the (unweighed) average share is 38\%. In countries that do not apply a WTP method (Australia, Germany and Singapore) this share is much lower, because WTP methods result in much higher values per casualty (see above). If these three countries are excluded, human costs have a share of about $50 \%$ in total costs. In LMICs the share of human costs is much lower (average 18\%) which is explained by the lower value of human losses per casualty.

In LMICs property damage has the largest share in the total costs (on average 39\%). It should be noted that the number of PDO crashes is uncertain because of (very) incomplete registration. In most countries assumptions have been used to estimate the number of PDO crashes. Two explanations for this relatively high share of PDO crashes are observed however. Firstly, human losses are valued relatively low in LMICs, which obviously leads to larger shares of the remaining components. Secondly, in LMICs the costs per PDO crash are relatively high as compared to costs that are injury related: the ratio of the costs of a PDO crash and the costs of a slight injury is two times higher in LMICs than in HICs, and the ratio of the costs of a PDO crash and the costs of a serious injury is even eight times higher in LIMCs (see also Table 5). Note that the share of PDO crashes in the total costs (Figure 1) is much lower than the share of total property damage. This is because fatal and injury crashes also result in property damage. Property damage has in particular a major share in the costs of slight injury crashes.

Beside human costs and property damage, production loss is an important cost component, having an average share in total costs of $21 \%$ in HICs and 23\% in LMICs. Medical costs are relatively low, particularly in HICs, as well as administrative costs.

Figure 2: distribution of the total cost of road crashes among cost components 


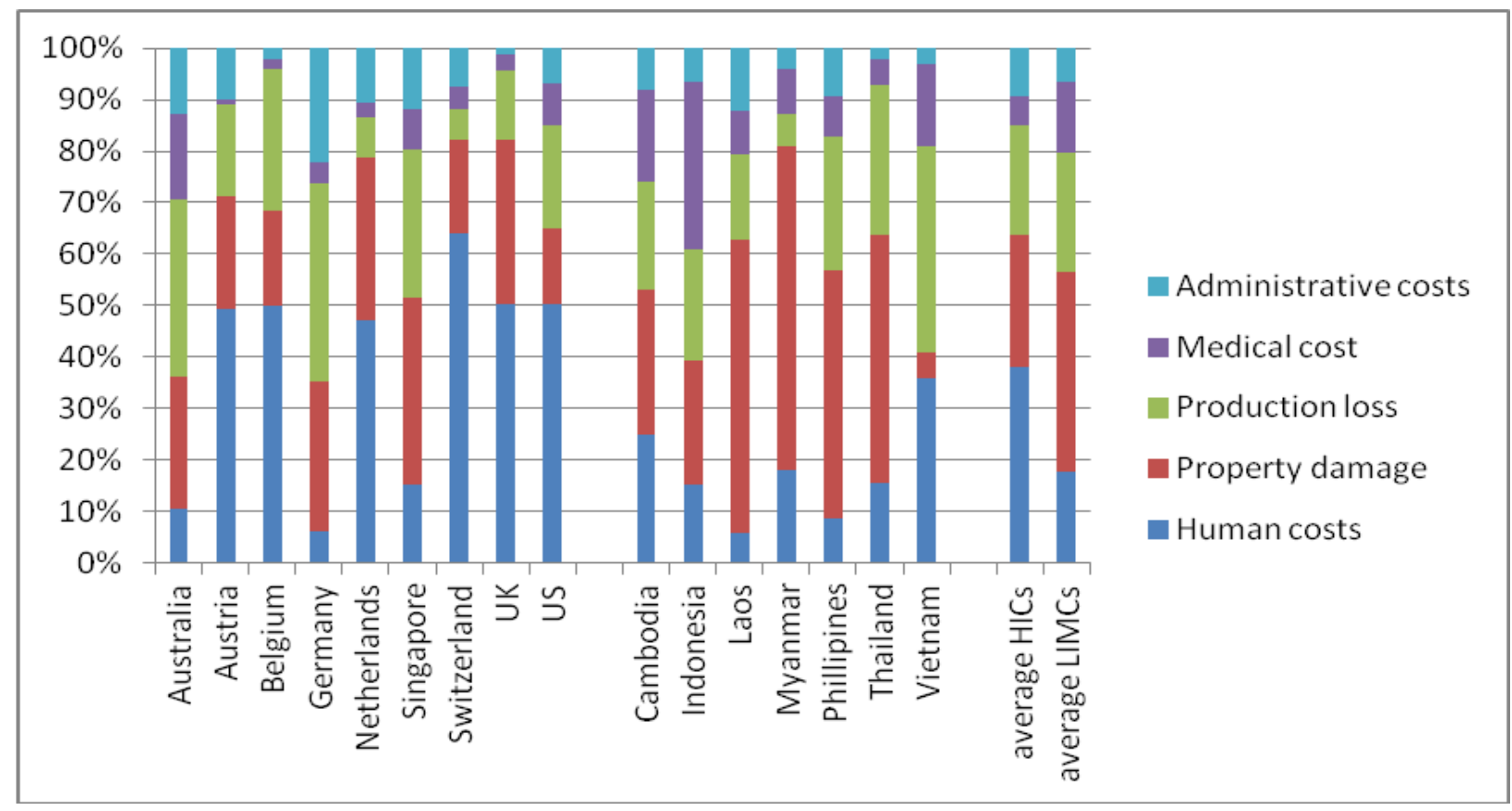

\section{DISCUSSION}

Regarding the methodology used to estimate road crash costs several differences between countries have been observed in our analysis. Although all countries in this overview take into account the cost components that have been recommended in international guidelines, some high income countries incorporate additional cost components and also within the main cost components there are differences. Additional costs components that are taken into account by most HICs are costs of congestion and costs of vehicle unavailability. The share of these additional costs in total costs is at most 7\%. Regarding production loss some countries take into account unpaid production loss (e.g. household work) and/or friction costs (costs of recruiting and training new personnel). Unpaid production may have a significant impact on the estimates of production loss, particularly in LMICs where a larger share of (e.g. agricultural) production is used for own consumption. Concerning property damage, a number of countries takes into account damage to infrastructure in addition to vehicle damage. The share of infrastructure damage in total property ranges from $1 \%$ to $20 \%$. Finally, there are some countries that do not take into account human costs of slight injuries.

Also differences between countries are observed regarding the methods used to estimate separate cost components, particularly regarding human costs. The cost figures for the countries included in this paper show that human costs have a large share in the total costs. However, this share depends to large extent on the method that is used to estimate these costs. In countries that use a WTP method, which is recommended by international guidelines, this share is about $50 \%$ or more, while in other countries it is about $5 \%$ to $35 \%$. There are just a few countries that use a country-specific estimate of the value of a statistical life, and these values tend to be outdated. Moreover, there are very few studies into the human costs of injuries. Since a major part of the human costs relates to injuries $(75 \%$ in HICs and $65 \%$ in LMICs, unweighed averages), particularly more research into the value of saving injuries is recommended. The LMICs in this overview do not apply WTP estimates, and therefore human (and total) costs are underestimated. Therefore, more research into human costs is 
recommendable particularly in LMICs. Difficulties may arise however because WTP studies in LMICs are complex for methodological (are poor people able to answer questions about small risks and their willingness to pay to reduce these risks?) and practical reasons (expensive studies). Using values from other countries may be a fruitful approach to cope with this, and thus the question how to 'transfer' values between (high and low) income countries is a relevant topic for future research.

Besides the issue of the methodology used to estimate human costs, problems are particularly faced regarding estimating property damage. Insurance data cover just a part of all property damage, because not all damage results in submitting a claim at an insurance company. Moreover, it is difficult to deduct the average damage per crash from insurance data, since smaller damage amounts are more likely not to be claimed. Also registration of property damage only crashes is poor, which makes it difficult to estimate these costs. Due to these difficulties the estimates of property damage are uncertain, as recognized in most cost studies. However, the current estimates indicate that property damage is a major costs component (24\% of total costs in HICs and 39\% in LMICs), and therefore research into these costs is recommended. Better information about these costs can be obtained by using questionnaires among road users about their involvement in crashes, the damage resulting from these crashes, and payments by insurance companies

In the literature standardized valuations, related to GDP or GDP per capita, have been used or proposed to estimate the costs of road crashes. Firstly, in calculations of the global costs of road crashes (Jacobs, 2000; WHO, 2004) the costs of road crashes have been estimated at a $1 \%$ (LMICs) to $2 \%$ (HICs). These percentages are rough estimates, and the figures for the countries discussed in this paper show that these percentages probably (hugely) underestimate the costs of road crashes. However, as the number of countries in this overview is limited, a study on a larger scale is recommended to obtain figures that are more representative on the global level. Secondly, the value of a fatality has been estimated at about 70 to 120 times GDP per capita on the basis of regression analysis (McMahon \& Dahdah, 2008; Miller, 2000). These ratios may be used as a rule of a thumb to estimate the costs per fatality and total costs of fatalities. As shown in this paper, the share of fatalities in total costs is limited however, and therefore estimating the costs of (all) injuries as well as property damage only crashes is needed to gain insight into the full social costs of road crashes. Furthermore, it is questionable whether road crash can be estimated on the basis of GDP (per capita) alone. Road safety performance, and so the costs of road crashes, depend on many factors like motorization rate, road safety investments, speed limits and culture, and these factors may not or only to a limited extent be related to GDP.

\section{CONCLUSIONS AND RECOMMENDATIONS}

In this overview the total costs of road crashes are found to be $2.6 \%$ of GDP in the HICs and $2.2 \%$ of GDP in the LMICs (unweighed averages). In (high income) countries that use a willingness to pay method to estimate human costs, as recommended in international guidelines, total road crash costs have a share of $3.7 \%$ in GDP. This is much higher than the percentages that have been used in previous studies to estimate global road crash costs.

A major part of the costs of road crashes is related to injuries: an average of about $55 \%$ in HICs and $50 \%$ in LMICs. The share of fatalities in the costs is 'only' $20 \%$ in HICs whereas in LMICs $30 \%$ of the costs is related to fatalities. This may indicate that the efforts in HICs to prevent fatalities have been effective, resulting in a lower economic burden of fatalities. The 
challenge for most HICs now is to bring down the (economic) burden of road injuries, particularly serious injuries, as well.

A number of methodological differences between countries have been observed. This concerns firstly the cost components that are taken into account. Although a cost classification as recommended by international guidelines is applied by all countries, there are differences regarding loss of unpaid production, property damage other than vehicle damage (particularly damage to infrastructure), human costs of slight injuries, congestion costs and costs of vehicle unavailability. Secondly, there are differences regarding the methods used to estimate specific cost components, especially with respect to human costs. In order to be able to make sound comparisons of the costs of road crashes across countries (further) harmonization of cost studies is recommended, e.g. by updating and improving international guidelines and applying them in future cost studies.

A cost component that is missing in cost studies as well as in international guidelines are avoidance costs: cost of adapting travel behaviour because of (perceived) low safety levels. No studies have been done yet regarding these safety costs, but there are examples of studies into the avoidance costs related to congestion. It is recommended to study the (potential) avoidance costs and develop methods to estimate these costs.

Finally, the information regarding some cost components is poor and more research into these cost components is recommended. This particularly regards human costs of fatalities in low and middle income countries, human costs of injuries (in all countries), and property damage.

\section{REFERENCES}

ADB (2005a). Arrive alive; ASEAN Commits to Cutting Road Deaths. Asian Development Bank - Association of Southeast Nations.

ADB (2005b). The cost of road traffic accidents in Cambodia. Asian Development BankAssociation of Southeast Nations.

ADB (2005c). The cost of road traffic accidents in Indonesia. Asian Development Bank Association of Southeast Nations.

ADB (2005d). The cost of road traffic accidents in Lao PDR. Asian Development BankAssociation of Southeast Nations.

ADB (2005e). The cost of road traffic accidents in Myanmar. Asian Development Bank Association of Southeast Nations.

ADB (2005f). The cost of road traffic accidents in the Philippines. Asian Development Bank - Association of Southeast Nations.

ADB (2005g). The cost of road traffic accidents in Singapore. Asian Development Bank Association of Southeast Nations.

ADB (2005h). The cost of road traffic accidents in Thailand. Asian Development Bank Association of Southeast Nations.

ADB (2005i). The cost of road traffic accidents in Vietnam. Asian Development BankAssociation of Southeast Nations.

Alfaro, J-L, Chapuis, M. \& Fabre, F. (1994). Socioeconomic cost of road accidents. Transport Research COST 313. Brussels/Luxembourg: Commission of the European Communities. 
Baum, H., Kranz, T. \& Westerkamp, U. (2007). Volkswirtschaftliche Kosten durch Straßenverkehrsunfälle in Deutschland. Heft M208. Bundesanstalt für Straßenwesen, Bergisch Gladbach.

Bickel, P., Friedrich, R., Burgess, A., Fagiani, P., Hunt, A. et al. (2006). Proposal for harmonised guidelines. EU project HEATCO Deliverable 5. Stuttgart: University of Stuttgart.

BITRE (2009). Costs of road crashes in Australia 2006. Research report 118. Bureau of Infrastructure, Transport and Regional Economics, Canberra.

Blincoe, L.J. Seay, A.G., Zaloshnja, E., Miller, T.R., Romano, E.O., Luchter, S. \& Spicer, R.S. (2002). The economic impact of motor vehicle crashes 2000. National Highway Safety Administration, Washington.

Boardman, A.E., Greenberg, D.H., Vining, A.R., Weimer, D.L. (2006). Cost-benefit analysis. Concepts and practice. Third edition. Pearson Prentice Hall, New Jersey.

Brabander, B. de. (2005). Investeringen in verkeersveiligheid in Vlaanderen; een handleiding voor kosten-batenanalyse. LannooCampus, Tielt.

Brabander, B. de. \& Vereeck, L. (2005). Verkeersongevallen in België kosten jaarlijks 12,5 milard. Verkeersspecialist, 122, pp. 23-26.

BRS\&TRL (2003). Guidelines for estimating the costs of road crashes in developing countries. Babtie Ross Silcock \& Transport Research Laboratory.

DfT (2011). A valuation of road accidents and casualties in Great Britain in 2010. In: DfT (2011), Reported Road Casualties in Great Britain: 2010 Annual Report. Department of Transport, Londen.

ECOPLAN (2002). Unfallkosten im Strassen- und Schienenverkehr der Schweiz 1998. ECOPLAN, Bern.

Elvik, R.(1995). An analysis of official economic valuations of traffic accident fatalities in 20 motorized countries. Accident Analysis and Prevention, vol. 27, nr. 2, pp. 237-347.

Elvik, R. (2000). How much do road accidents cost the national economy? Accident Analysis and Prevention, vol. 32, nr. 6, pp. 849-851.

Evans, A. (2001). The economic appraisal of road traffic safety measures in Great Britain. Paper for ECMT Round Table 117 "Economic evaluation of road traffic safety measures". ECMT, Paris.

Hakkert, S. \& Wesemann, P. (eds.) (2005). The use of efficiency assessment tools: solutions to barriers. Workpackage 3 of the European research project ROSEBUD. R-2005-2. SWOV, Leidschendam.

Herry, ZTL \& KfV (2008). Unfallkostenrechnung Straße 2007. Herry Consult GmbH, Zentrum Transportwirtschaft und Logistik \& Kuratorium für Verkehrssicherheit, Wenen.

Hopkin, J.M. \& O'Reilly, D.M. (1993). Revaluation of the cost of road accident casualties: 1992 revision. TRL Research Report 378. Transport Research Laboratory, Crowthorne.

Jacobs, G. Aeron-Thomas, A. \& Astrop, A. (2000). Estimating global road fatalities. TRL report 445.

KiM (2012). Mobiliteitsbalans 2012. Kennisinstituut voor Mobiliteitsbeleid, The Hague.

McMahon, K. (1994). Valuation of road accidents1994. In: DfT (1994), Road accidents Great Britain 1994: the casualty report. Department of Transport, Londen.

McMahon, K. \& Dahdah, S. (2008). The true costs of road crashes. International Road Assessment Programme iRAP. 
Miller, T.R. (2000). Variations between countries in values of statistical life. Journal of Transport Economics and Policy, vol. 34, nr. 2, pp. 169-188.

Nellthorp, J., T. Sansom, P. Bickel, C. Doll, G. Lindberg (2001). Valuation Conventions for UNITE (UNIfication of accounts and marginal costs for Transport Efficiency). Funded by 5th Framework RTD Programme. ITS, University of Leeds, Leeds.

OECD (2012). Economics: Key tables from OECD. 14 November 2012.

O'Reilly, D. Hopkin, J. Loomes, G. Jones-Lee, M. Philips, P. McMahon, K. Ives, D. Soby, B. Ball, D. \& Kemp, R. (1994). The value of road safety. UK research on the valuation of preventing non-fatal injuries. Journal of Transport Economics and Policy, 28(1), 45-59.

Persson (2004). Valuing reductions in the risk of traffic accidents based on empirical studies in Sweden. Thesis. Lund Institute of Technology, Zweden.

Sommer, H., Brügger, O., Lieb, C. \& Niemann, S. (2007). Volkswirtschaftliche Kosten der Nichtberufsunfälle in der Schweiz; Strassenverkehr, Sport, Haus und Freizeit. Beratungsstelle für Unfallverhütung, Bern.

SWOV (2011). Road crash costs. Factsheet. SWOV, Leidschendam.

SWOV (2012). The valuation of human losses of road deaths. Factsheet. SWOV, Leidschendam.

Taylor, M.C. (1990). The cost of vehicle damage resulting from road accidents. TRL Research Report 256. Transport Research Laboratory, Crowthorne.

Trawén, A., Maraste, P. \& Persson, U. (2002). International comparison of costs of a fatal casualty of road accidents in 1990 and 1999. Accident Analysis and Prevention, vol. 34, nr. 3, p. 323-332.

TRL (1995). Costing Road Accidents in Developing Countries. Overseas Road Note 10. Transport Research Laboratory, Crowthorne.

Van Wee, B., Hagenzieker, M \& Wijnen, W. (forthcoming). Which indicators to include in the ex ante evaluations of safety effects of policy options? An ethical perspective. Accepted for publication in Transport Policy.

WHO (2004). World report on road traffic injury prevention. World Health Organization.

Wijnen, W., Wesemann, P. \& de Blaeij (2009). Valuation of road safety effects in cost-benefit analysis. Evaluation and Program Planning, 32, pp. 326-331.

Wijnen, W. (2012). Bouwstenen voor de berekening van de kosten van verkeersongevallen 2003-2009. D-2012-4. SWOV, Leidschendam.

Wit, M. de \& Methorst, R. (2012). Kosten verkeersongevallen in Nederland; Ontwikkelingen 2003-2009. Directoraat-Generaal Rijkswaterstaat, Dienst Verkeer en Scheepvaart, Rotterdam.

World Bank (2012). World Development Indicators \& Global Development Finance. 19 July 2012. 